\title{
Comparing Transcervical Intrauterine Lidocaine Instillation with Rectal Diclofenac for Pain Relief During Outpatient Hysteroscopy: A Randomized Controlled Trial
}

Original

Article

\author{
Amro S. El-Houssieny, Haitham A. Sabba, Heba A. Allam, Mohamed A. Abozeid \\ Department of Obstetrics and Gynecology, Faculty of Medicine, Ain-Shams University, Cairo, \\ Egypt
}

\begin{abstract}
Background: Outpatient hysteroscopy is a clinical procedure that is used for several diagnostic and therapeutic purposes. However, the most common adverse event and reason for procedure failure is pain. Several strategies were developed to manage pain during outpatient hysteroscopy.

Aim: The aim of the present study is to compare the efficacy of intrauterine lidocaine instillation and rectal diclofenac in reducing pain associated with outpatient hysteroscopy.

Materials and Methods: The present study was a randomized, comparative, trial that included. 200 female patients who underwent outpatient hysteroscopy at office hysteroscopy room at early cancer detection unit of Ain-Shams Maternity Hospital. The patients were randomly allocated to receive transcervical intrauterine instillation of $5 \mathrm{ml} 2 \%$ lidocaine or $100 \mathrm{mg}$ rectal diclofenac.

Results: The most common cause for undergoing infertility, followed by menorrhagia and irregular uterine bleeding. In addition, the most common findings were submucous fibroid, endometrial polyp, and intrauterine adhesion. Regarding the primary outcome of the present study, it was found that the $100 \mathrm{mg}$ rectal diclofenac was more effective than intrauterine instillation of $5 \mathrm{ml} \mathrm{2} \%$ lidocaine for pain relief during outpatient hysteroscopy. Both drugs were tolerable with no observed adverse events.

Conclusion: Rectal diclofenac was more effective than local anesthetic in pain relief during outpatient hysteroscopy. This technique may be ideal for outpatient diagnostic hysteroscopy. However, further well-designed studies are still needed to confirm this finding.
\end{abstract}

Key Words: Hysteroscopy, instillation, lidocaine, pain relief, rectal diclofenac, transcervical intrauterine

Received: 03 January 2020, Accepted: 13 April 2020

Corresponding Author: Mohamed A. Abozeid, Department of Obstetrics and Gynecology, Faculty of Medicine, Ain-Shams University, Egypt, Tel.: 01112337848, E-mail: mohamedabozeid098@gmail.com

ISSN: 2090-7265, August 2020, Vol.10, No. 3

\section{INTRODUCTION}

Outpatient hysteroscopy is an established diagnostic test that is in widespread use across the world. The procedure involves the use of miniaturized endoscopic equipment to directly visualize and examine the uterine cavity, without the need for formal theatre facilities or general or regional anesthesia. Outpatient hysteroscopy is indicated primarily in the assessment of women with abnormal uterine bleeding, but is also employed in the diagnostic work-up of reproductive problems ${ }^{[1]}$.

More recently, advances in endoscopic technology and ancillary instrumentation have facilitated the development of operative hysteroscopic procedures in an outpatient setting with or without the use of local anesthesia. Common procedures include endometrial polypectomy, Removal of small submucous fibroids, endometrial ablation,
Removal of lost intrauterine devices and transcervical sterilisation $^{[2]}$.

Outpatient hysteroscopy, whether diagnostic or operative, is successful, safe and well tolerated. However, as with any procedure requiring instrumentation of the uterus, outpatient hysteroscopy can be associated with significant pain, anxiety and embarrassment. This not only impacts upon women's satisfaction with their experience, but also limits the feasibility and possibly the safety, accuracy and effectiveness of the procedure. To minimize pain and discomfort, variations in hysteroscopic equipment, adaptations to the technique and use of pharmacological agents have been advocated ${ }^{[3]}$.

Severe pain and patient anxiety are among the most common causes of surgical failure. Many anesthetic options are available to patients undergoing hysteroscopy. 
A Cochrane review supports the use of local anesthesia as effective pain control during and within 30 minutes of completing hysteroscopy ${ }^{[4]}$.

Conventional panoramic hysteroscopy requires some form of anesthesia, while the smaller caliber flexible hysteroscopes require little to no anesthesia. For hysteroscopes of larger diameter, injectable local anesthetic combined with preoperative vaginal misoprostol (Cytotec) is usually sufficient. Occasionally, regional anesthesia, monitored anesthesia care (MAC), or general anesthesia may be indicated for more extensive procedures or for patients who have lower pain tolerance and/or anxiety ${ }^{[5]}$.

Many practitioners favor the use of topical anesthesia, although studies have shown mixed efficacy. Aerosolized preparations of lidocaine may decrease cervical pain from tenaculum placement but do not decrease uterine sensation. Additionally, a study comparing the addition of lidocaine with the saline distension media showed no difference in pain score compared with saline alone $\mathrm{e}^{[5]}$.

In contrast, transcervical instillation of $5 \mathrm{~mL}$ of $2 \%$ mepivacaine lowered pain scores and decreased the rate of vasovagal reactions for women undergoing diagnostic hysteroscopy followed by endometrial biopsy. Topical anesthetics typically do not provide long-lasting relief but may be sufficient for the non-anesthetized woman ${ }^{[6]}$.

Infiltration of the paracervical tissue with a local anesthetic is commonly used for hysteroscopic anesthesia. A paracervical block can decrease the pain of tenaculum placement, cervical dilation, and hysteroscope insertion through the cervix. However, paracervical anesthesia has less effect on the pain of uterine distension ${ }^{[7]}$. One must balance the expected pain of the hysteroscopic procedure with the pain and potential side-effects of the paracervical block, which include bradycardia and hypotension. For these reasons, many providers choose to forgo this step, especially for brief diagnostic procedures. Common anesthetic agents are $1 \%$ lidocaine, mepivacaine, prilocaine, ropivacaine, bupivacaine, and etidocaine. Of these, bupivacaine and etidocaine have longer durations and can last upwards of 2-3 hours $^{[8]}$.

A recent study suggests that paracervical ropivacaine controls intraoperative pain slightly better than lidocaine during surgical abortions. In most cases, $10 \mathrm{~mL}$ of bupivacaine $0.25 \%$, mepivacaine $1 \%$, or lidocaine $1-2 \%$ is an adequate volume for paracervical anesthesia. If more volume is required, understanding the safe doses for each particular agent is important. For example, the toxic dose of lidocaine is approximately $4.5 \mathrm{mg} / \mathrm{kg}$ for a $70-\mathrm{kg}$ woman, $4.5 \mathrm{mg} / \mathrm{kg} \times 70 \mathrm{~kg}=315 \mathrm{mg}$, or $31.5 \mathrm{~mL}$ of lidocaine $1 \%{ }^{[7]}$

Intrauterine instillation of topical anesthetic is easy, relatively painless, and promising as an adequate analgesia during diagnostic hysteroscopy. This technique could be the ideal anesthesia for women undergoing outpatient diagnostic hysteroscopy. Since rectal NSAIDs act more rapidly than the oral form and there was no study for rectal use of these drugs for hysteroscopy, so this study will compare the efficacy of intrauterine lidocaine instillation with rectal diclofenac for pain relief in women undergoing diagnostic hysteroscopy ${ }^{[9]}$.

\section{AIM OF THE WORK}

This study aims to compare the efficacy of intrauterine lidocaine instillation and rectal diclofenac in reducing pain associated with outpatient hysteroscopy.

\section{PATIENTS AND METHODS}

The present randomized controlled trial was conducted on 200 women aged 18-35 years old and scheduled for diagnostic hysteroscopy; 100 in intrauterine lidocaine instillation group (Lidocaine group) and 100 in rectal diclofenac group (Voltaren group) at office hysteroscopy room of early cancer detection unit (ECDU) of Ain-Shams Maternity Hospital during the period from $1^{\text {st }}$ May 2018 to $1^{\text {st }}$ November 2018.

The study included nulliparous women with ages between 18-35, BMI between $18-30 \mathrm{~kg} / \mathrm{m}$ with abnormal uterine bleeding and complaining of infertility. However, respiratory or cardiac dysfunction, previous adverse reaction to any of the drugs used in the study and patients having inability to understand how to score the pain were excluded from the study.

Procedures and interventions: In the gynecologic ward, 30 minutes before transferring to the operating room, the staff gave $100 \mathrm{mg}$ rectal diclofenac to women in the diclofenac group ; while in the lidocaine group, patients were put in the lithotomy position and a sterile bivalve speculum was introduced into the vagina for visualization of the cervix. The cervix and vagina were washed with antiseptic solution. The cervix was grasped with singletoothed tenaculum to straighten the uterine axis. Lidocaine will be prepared by the anesthesia staff who gave it to the surgeon who was blinded to allocation. Then $5 \mathrm{ml}$ of $2 \%$ lidocaine will be instilled through the endocervix into the uterine cavity with an 18- gauge angiocatheter. The angiocatheter was left in place for three minutes before it was withdrawn while patients were in the Trendelenburg position to limit backflow and to allow the anesthetic to take effect. All members of the surgical team, nursing staff, patients, and the anesthetist will be unaware of the allocation.

Before surgery, patients were educated about the WongPaker faces pain rating scale which is based on a numeric pain rating scale from 0 - 10 , with zero being no pain and 10 being the worst pain imaginable. 
The scale includes numbers, faces (visual representation) and written descriptions. There are 6 faces in the Wong-Baker Pain Scale. The first face represents a pain score of 0 and indicates no hurt. The second face represents a pain score of 2 and indicates hurts a little bit. The third face represents a pain score of 4 and indicates hurts a little more. The fourth face represents a pain score of 6 and indicates hurts even more. The fifth face represents a pain score of 8 and indicates hurts a whole lot and the sixth face represents a pain score of 10 and indicates hurts worst.

Patients were asked about the degree of pain immediate after the procedure. The following data were collected from the patients detailed history taking, presenting complaints, hysteroscopy findings and pain score during the procedure.

\section{Ethical considerations:}

It was confirmed that the present study run in concordance with international ethical standards and applicable local regulatory guidelines. The study does not have any physical, psychological, social, legal, economic, or any other anticipated risks to study's participants. The study conserves participants' privacy. Investigators are responsible for keeping the security of the data. It was also confirmed that the participants' data were not used for any other purpose outside this study.

Personal data (e.g. name, contact info) were not entered in this data entry software to conserve the participants' privacy; however, each subject got a unique identifier code. A written informed consent was obtained from every eligible woman. Women were informed about the study objectives, methodology, risk and benefit.

\section{STATISTICAL ANALYSIS}

An Excel spreadsheet was established for the entry of data. A validation checks on numerical variables and option-based data entry method for categorical variables to reduce potential errors was used. The analyses were carried with SPSS software (Statistical Package for the Social Sciences, version 24, SSPS Inc, Chicago, IL, USA)

Frequency tables with percentages were used for categorical variables and descriptive statistics (median and interquartile range $[\mathrm{IQR}]$ ) were used for numerical variables. Independent Student t-test, paired t-test, or Mann-Whitney tests were used to compare quantitative variables, while Chi-square test or McNemar-Bowker tests were used to analyze categorical variables. A $p$-value $<0.05$ is considered statistically significant.

\section{RESULTS}

The mean age was $28.58 \pm 4.87$ and the mean BMI was $25.97 \pm 2.46 \mathrm{~kg} / \mathrm{m} 2$. The median number of abortions was 2 (1-3). The most common cause for undergoing $\mathrm{OH}$ was infertility, followed by menorrhagia and irregular uterine bleeding.

The most common findings were NAD (40\%), submucous fibroid (18\%), endometrial polyp (13\%), and intrauterine adhesion $(11.5 \%)$. The median pain score was $4(2-6)$.

There were no statistically significant associations between studied group and complaints $(p=0.414)$.

There was statistically significant association between studied group and pain score $(p<0.001)$. Women in Voltaren group were more likely to have lower pain score.

There was statistically significant positive correlation between age and pain score $(r=0.164, p=0.021)$.

There was no statistically significant association between complaint and pain score $(r=0.435)$.

Table 1: The demographic and clinical characteristics of the included patients

\begin{tabular}{lcc}
\hline & & Total no. $=200$ \\
\hline \multirow{2}{*}{ Age } & Mean \pm SD & $28.58 \pm 4.87$ \\
& Range & $18-35$ \\
BMI & Mean \pm SD & $25.97 \pm 2.46$ \\
& Range & $20.2-30$ \\
Abortion & Median (IQR) & $2(1-3)$ \\
& Range & $0-5$ \\
& Infertility & $139(69.5 \%)$ \\
& Menorrhagia & $17(8.5 \%)$ \\
Complaint & Oligomenorrhea & $14(7.0 \%)$ \\
& Amenorrhea & $2(1.0 \%)$ \\
& Irreg. ut. Bleeding & $27(13.5 \%)$ \\
\hline
\end{tabular}


Table 2: The procedure characteristics of the included patients

\begin{tabular}{|c|c|c|}
\hline & & Total no. $=200$ \\
\hline \multirow[t]{17}{*}{ Finding } & NAD & $80(40.0 \%)$ \\
\hline & Intrauterine adhesion & $23(11.5 \%)$ \\
\hline & Submucous fibroid & $36(18.0 \%)$ \\
\hline & Endometrial polyp & $26(13.0 \%)$ \\
\hline & Uterine septum & $19(9.5 \%)$ \\
\hline & Depressed fundus & $2(1.0 \%)$ \\
\hline & Thick irregular endometrium & $2(1.0 \%)$ \\
\hline & Fundul depression & $1(0.5 \%)$ \\
\hline & Cavity filled with soft tissue & $1(0.5 \%)$ \\
\hline & Left tubal obstruction & $1(0.5 \%)$ \\
\hline & Submucous fibroid \& left tube obstruction & $1(0.5 \%)$ \\
\hline & Thick polypoidal endometrium & $2(1.0 \%)$ \\
\hline & Arcuate uterus & $1(0.5 \%)$ \\
\hline & Tubal cavity & $1(0.5 \%)$ \\
\hline & Multiple fibroid & $1(0.5 \%)$ \\
\hline & Endometrial polyp + uterine septum & $1(0.5 \%)$ \\
\hline & Failed & $2(1.0 \%)$ \\
\hline \multirow[t]{2}{*}{ Procedure } & Voltarine & $100(50.0 \%)$ \\
\hline & Lidocaine & $100(50.0 \%)$ \\
\hline \multirow[t]{2}{*}{ Pain score } & Median (IQR) & $4(2-6)$ \\
\hline & Range & $2-8$ \\
\hline
\end{tabular}

Table 3: Association between studied group and complaints

\begin{tabular}{lcccc}
\hline Complaint & Voltaren group & Lidocaine group & Test \\
& No. $=100$ & No. $=100$ & P-value & Sig. \\
\hline Infertility & $69(69.0 \%)$ & $70(70.0 \%)$ & & \\
Menorrhagia & $10(10.0 \%)$ & $7(7.0 \%)$ & & NS \\
Oligomenorrhea & $5(5.0 \%)$ & $9(9.0 \%)$ & 5.013 & 0.414 \\
Amenorrhea & $0(0.0 \%)$ & $2(2.0 \%)$ & & \\
Irreg. ut. Bleeding & $15(15.0 \%)$ & $12(12.0 \%)$ & & \\
Vesicular mole & $1(1.0 \%)$ & $0(0.0 \%)$ & & \\
evacuation & & & \\
\hline
\end{tabular}

$P$-value $>0.05$ : Non significant; $P$-value $<0.05$ : Significant; $P$-value $<0.01$ : Highly significant

*: Chi-square test 
Table 4: Association between studied group and pain score

\begin{tabular}{lcccc}
\hline Pain score & Voltaren group & Lidocaine group & & Test value $\neq$ \\
& No. $=100$ & No. $=100$ & & Sig. \\
Median (IQR) & $2(2-4)$ & $6(6-8)$ & -11.459 & 0.000 \\
Range & $2-6$ & $2-8$ & & HS \\
\hline
\end{tabular}

Table 5: Correlation between studied variables and pain score

\begin{tabular}{lcc}
\hline & Pain score \\
\hline & r & \\
& & \\
Age & $0.164^{*}$ & 0.021 \\
BMI & 0.061 & 0.396 \\
Abortion & -0.006 & 0.949 \\
\hline
\end{tabular}

$P$-value $>0.05$ : Non significant; $P$-value $<0.05$ : Significant; $P$-value $<0.01$ : Highly significant Spearman correlation coefficient

Table 6: Association between pain score and complaint

\begin{tabular}{|c|c|c|c|c|c|}
\hline \multirow[t]{2}{*}{ Complaint } & \multicolumn{2}{|c|}{ Pain score } & \multirow{2}{*}{ Test value } & \multirow{2}{*}{ P-value } & \multirow{2}{*}{ Sig. } \\
\hline & Median (IQR) & Range & & & \\
\hline Infertility & $4(2-6)$ & $2-8$ & & & \\
\hline Menorrhagia & $6(2-6)$ & $2-8$ & & & \\
\hline \multirow[t]{2}{*}{ Oligomenorrhea } & $6(4-6)$ & $2-8$ & & & \\
\hline & & & 2.731 & 0.435 & NS \\
\hline Amenorrhea & $7(6-8)$ & $6-8$ & & & \\
\hline Irreg. ut. Bleeding & $4(2-6)$ & $2-8$ & & & \\
\hline $\begin{array}{l}\text { Vesicular mole } \\
\text { evacuation }\end{array}$ & $2(2-2)$ & $2-2$ & & & \\
\hline
\end{tabular}




\section{DISCUSSION}

Outpatient hysteroscopy is a clinical procedure that is used for several diagnostic and therapeutic purposes. Diagnostic utilities include biopsy of the endometrium, identifying the source of abnormal uterine bleeding, as well structural endometrial abnormalities. Therapeutic uses include endometrial polypectomy and removal of lost intrauterine devices. The procedure has several advantages: lower cost, no need for general or regional anesthesia, and lower rates of complications ${ }^{[10]}$.

However, the most common adverse event and reason for procedure failure is pain. It originates during different steps of the procedure: passage of the tenaculum through the cervical canal, uterine distension, and spill of the dilatation fluid into the peritoneum, causing peritoneal irritation. Other factors may be involved, such as endometrial destruction and release of prostaglandins from such endometrium (which may account for the reported delayed pain, after 30 minutes of the procedure $)^{[11]}$.

Several strategies were developed to manage pain during outpatient hysteroscopy. Several research groups recommend the no-touch technique (avoiding tenaculum use, using vaginoscopy and cervical hydrodistention). However, it is not always possible and may still be associated with pain. Therefore, different analgesic methods have been evaluated for this regard. These methods range from various pharmacological agents as non-steroidal antiinflammatory drugs (NSAIDs), opioids, and local anesthetics to non- pharmacological interventions as hypnosis, heat, and transcutaneous electric nerve stimulation (TENS); which of these methods is superior in clinical practice remains widely unknown. In fact, a survey of clinical practices in the UK revealed marked variations in the used analgesic methods for outpatient hysteroscopy ${ }^{[12]}$.

Because of the prevalence and burden of pain in this procedure, determination of the best analgesic methods would inform clinical practice and improve patient care. Therefore, the present study was conducted in order to compare the efficacy of transcervical intrauterine lidocaine instillation versus rectal diclofenac in reducing pain during outpatient hysteroscopy. In terms of demographic characteristics of the included patients, the mean age was $28.58 \pm 4.87$ and the mean BMI was $25.97 \pm 2.46 \mathrm{~kg} / \mathrm{m} 2$.

Diagnostic hysteroscopy is an accurate and less invasive method for the evaluation of common gynecological disorders such as premenopausal or postmenopausal abnormal uterine bleeding (AUB), endometrial hyperplasia, endometrial cancer and infertility ${ }^{[13]}$.
In the present study, the most common cause for undergoing infertility followed by menorrhagia and irregular uterine bleeding. In addition, the most common findings were submucous fibroid, endometrial polyp and intrauterine adhesion. In line with these findings, Shawki and colleagues ${ }^{[14]}$ assessed the incidence of undiagnosed intrauterine pathology based on screening office hysteroscopy in women. In El-Menya Infertility Research and Treatment Center (MIRTC) (El-Menya, Egypt), 240 patients were eligible to participate in the study. The most commonly encountered uterine pathologies were submucous fibroid, endometrial polyp and intrauterine adhesion; while, Karayalcin and colleagues ${ }^{[15]}$ assessed the diagnostic accuracy findings and feasibility of officebased diagnostic hysteroscopy in an IVF population. A total of 2500 consecutive infertile patients were enrolled prospectively prior to IVF treatment. Diagnostic hysteroscopy was performed on each subject in an office setting in the study IVF center. A total of 1927 patients $(77.1 \%)$ had a normal uterine cavity, while the remainder of the sample $(\mathrm{n}=573)$ demonstrated endometrial pathology on hysteroscopy (22.9\%). Out of the patients with endometrial pathology, 192 patients had endometrial polyps (7.68\%), 96 patients had submucosal fibroids (3.84\%), 31 patients had polypoid endometria $(1.24 \%)$ and 27 patients had intrauterine adhesions (1.08\%).

Lidocaine, an aromatic benzene ring connected to an amide group, is a local anesthetic agent which inhibits the influx of sodium into the cell, thus preventing the occurrence of the neurotransmitter cascade. It has a rapid onset, short duration of action, low cost, minimal side effects and good availability. Recent literature showed that intrauterine lidocaine and bupivacaine instillation were appropriate methods for pain relief during intrauterine procedures ${ }^{[16]}$.

On the other hand, rectal NSAIDs act more rapidly than the oral form. Diclofenac is a NSAID which has analgesic and antipyretic activities. This drug is readily absorbed from the alimentary tract and its half time is about one to two hours, and it will quickly dissolve in an environment with a $\mathrm{pH}$ higher than five. Diclofenac as one of the most potent NSAID has a few side effects when administered rectally ${ }^{[17]}$.

Regarding the primary outcome of the present study, it was found that the $100 \mathrm{mg}$ rectal diclofenac was more effective than intrauterine instillation of $5 \mathrm{ml} \mathrm{2 \%}$ lidocaine for pain relief during outpatient hysteroscopy. Both drugs were tolerable with no observed adverse events.

In concordance with these findings, Mohammadi and colleagues ${ }^{[17]}$ conducted a double-blind randomized controlled trial on 70 nulliparous women with primary 
infertility undergoing diagnostic hysteroscopy. Subjects were assigned into one of two groups to receive either $100 \mathrm{mg}$ of rectal diclofenac or $5 \mathrm{~mL}$ of $2 \%$ intrauterine lidocaine. The mean pain score was significantly lower during insertion and extrusion of the hysteroscope in the diclofenac group $(p=0.001$ and $p=0.030$, respectively).

To the best of our knowledge, this study is the second trial of its kind that evaluated the efficacy of rectal diclofenac versus lidocaine for pain relief during office hysteroscopy. However, previous studies assessed oral diclofenac or other local anesthetics for pain relief during office hysteroscopy.

El-Gamal and colleagues (18) assessed the analgesic efficacy of lidocaine dissolved in the distension medium compared to oral diclofenac before outpatient diagnostic hysteroscopy. The study was a randomized controlled trial including 44 nulliparous women schedules to undergo diagnostic office hysteroscopy. The participants were randomly categorized into two groups; group $\mathrm{D}(\mathrm{n}=22)$ received diclofenac 100 $\mathrm{mg}$ oral tablets and group $\mathrm{L}(\mathrm{n}=22)$ received $10 \mathrm{ml}$ of lidocaine $2 \%$ dissolved in saline (the distension medium). Group L showed significantly higher pain scores with hysteroscopic insertion $(p=0.017)$.

In another study by Sharma et al., ${ }^{[19]}$ on 120 women undergoing hysteroscopy and endometrial biopsy, there was significant reduction in the mean pain score with the use of oral drotaverine hydrochloride and mefenamic acid compared to paracervical block and intravenous sedation using diazepam. Although they used oral NSAIDs plus drotaverine, a selective inhibitor of phosphodiesterase 4, their results correlated with ours.

Anticipation for the need of premedication or additional analgesia to relieve pain during the procedure may reduce the failure rate of office hysteroscopy. This reduces psychological burden on the patient and increases the effectiveness of the medical service provided. In evaluating different predictors of pain, several studies have reported controversial results for the significance of clinical variables, such as parity, mode of delivery and menopausal status, presence of cesarean section scar etc. Moreover, the effect of surgeon's experience and diameter of the scope have been controversial in other studies ${ }^{[20]}$.

In the present study, it was found that the hysteroscopy-associated pain was correlated with patient's age only. Similarly, Carta and colleagues $^{[21]}$ conducted an observational study on 284 women undergoing hysteroscopy. Pain $(\geq 4)$ was significantly associated with age.
Additionally, Paulo and colleagues ${ }^{[22]}$ compared two centers where hysteroscopy is performed without general anesthesia or sedation in an office setting. This was a prospective observation multicenter study, comparing pain in-office hysteroscopy with three groups: mini-hysteroscopy (3 $\mathrm{mm}$ scope), conventional $(5 \mathrm{~mm})$ hysteroscopy without anesthesia and $(5 \mathrm{~mm})$ hysteroscopy with hysteroscopic anesthesia. The mean age tended to be higher and statistically significant in the group of women who reported more pain and where lidocaine was administered.

\section{CONCLUSION}

In conclusion, both rectal diclofenac intrauterine instillation of a topical anesthetic is easy, relatively painless and promising for adequate analgesia during office hysteroscopy. The present study showed that rectal diclofenac was more effective than local anesthetic in pain relief during outpatient hysteroscopy. This technique may be ideal for outpatient diagnostic hysteroscopy. However, further well-designed studies are still needed to confirm our finding.

\section{CONFLICT OF INTEREST}

There are no conflicts of interests.

\section{REFERENCES}

1. Van Dongen H, De Kroon CD, Van Den Tillaart SAHM, Louwé LA, Trimbos- Kemper GCM, Jansen FW. A randomised comparison of vaginoscopic office hysteroscopy and saline infusion sonography: A patient compliance study. BJOG An Int $\mathrm{J}$ Obstet Gynaecol 2008;115:1232-7.

2. Cooper NA, Clark TJ. Ambulatory hysteroscopy. The obstetrician \& gynaecologist. 2013;15(3):159-66.

3. ROCG. Best Practice in Outpatient Hysteroscopy. Green-top Guideline No.59, 2011.

4. Saluja S, Ahmad G, O'Flynn H, Watson A, Leach D. Pain relief for outpatient hysteroscopy: Cochrane database of systematic reviews. Bjog: An International Journal of Obstetrics and Gynaecology. 2016; 123.

5. Nelson AL, Fong JK. Intrauterine infusion of lidocaine does not reduce pain scores during IUD insertion. Contraception. 2013; 88(1):37-40. 
6. Sohn HM, Ryu JH. Monitored anesthesia care in and outside the operating room. Korean journal of anesthesiology. 2016; 69(4):319.

7. Soriano D, AJAJ S, Chuong T, Deval B, Fauconnier A, Daraï E. Lidocaine spray and outpatient hysteroscopy: Randomized placebo-controlled trial. Obstet Gynecol 2000;96:661-4.

8. Schorge JO, Schaffer JI, Halvorson LM, Hoffman BL, Bradshaw KD, Cunningham FG. Williams Gynecology. 1. New York: McGraw-Hill Medical; 2008.

9. Simpson D, Curran MP, Oldfield V, Keating GM. Ropivacaine: a review of its use in regional anaesthesia and acute pain management. Drugs. 2005; 65(18):2675-717.

10. Mohammadi SS, Abdi M, Movafegh A. Comparing transcervical intrauterine lidocaine instillation with rectal diclofenac for pain relief during outpatient hysteroscopy: a randomized controlled trial. Oman medical journal. 2015; 30(3):157.

11. McDonough PG, Ezeh UO. Outpatient Hysteroscopy-Paracervical Block. Fertil Steril 2019;64:221-2.

12. Ahmad G, Saluja S, O’Flynn H, Sorrentino A, Leach D, Watson A. Pain relief for outpatient hysteroscopy. Cochrane Database Syst Rev 2017. doi:10.1002/ 14651858.CD007710.pub3.

13. Lopez-Yarto M. Pain Management In-Office Hysteroscopy in Postmenopausal Women. Hysteroscopy, 2018, 123-30.

14. Daniilidis A, Pantelis A, Dinas K, Tantanasis T, Loufopoulos PD, Angioni S, et al. Indications of diagnostic hysteroscopy, a brief review of the literature. Gynecol Surg 2012;9:23-8.

15. Shawki HE, Elmorsy M, Eissa MK. Routine office hysteroscopy prior to ICSI and its impact on assisted reproduction program outcome: A randomized controlled trial. Middle East Fertil Soc J 2012;17:14-21. doi:10.1016/j. mefs.2011.04.005.
16. Karayalcin R, Ozcan S, Moraloglu O, Ozyer S, Mollamahmutoglu L, Batioglu S. Results of 2500 office-based diagnostic hysteroscopies before IVF. Reprod Biomed Online 2010;20:689-93. doi:10.1016/ j.rbmo.2009.12.030.

17. Benchahong S, Chanthasenanont A, Pongrojpaw D, Pattaraarchachai J, Bhamarapravatana K, Suwannarurk K. Efficacy of intrauterine lidocaine instillation in reducing pain during endometrial biopsy by Novak. Pain Res Treat 2018;2018. doi:10.11559368298/2018/.

18. Bakhsha F, Niaki AS, Jafari SY, Yousefi Z, Aryaie M. The effects of diclofenac suppository and intravenous acetaminophen and their combination on the severity of postoperative pain in patients undergoing spinal anaesthesia during cesarean section. J Clin Diagnostic Res 2016;10:UC09-12.

19. El-Gamal HH, Elbohoty AEH, Ahmed ME. Lidocaine Infusion on Hysteroscopic Media versus Oral Diclofenac for Pain Relief during Outpatient Hysteroscopy: A Randomized Controlled Trial. Egypt J Hosp Med 2018;69:2143-8.

20. Sharma J, Aruna J, Kumar P, Roy K, Malhotra N, Kumar S. Comparison of efficacy of oral drotaverine plus mefenamic acid with paracervical block and with intravenous sedation for pain relief during hysteroscopy and endometrial biopsy. Indian J Med Sci 2009a;63:244.

21. Campo R, Molinas CR, Rombauts L, Mestdagh G, Lauwers M, Braekmans P, et al. Prospective multicentre randomized controlled trial to evaluate factors influencing the success rate of office diagnostic hysteroscopy. Hum Reprod 2005;20:258-63.

22. Carta G, Palermo P, Marinangeli F, Piroli A, Necozione S, De Lellis V, et al. Waiting Time and Pain During Office Hysteroscopy. J Minim Invasive Gynecol 2012;19:360-4.

23. Paulo AAS, Solheiro MHR, Paulo COS. Is pain better tolerated with mini-hysteroscopy than with conventional device? A systematic review and meta-analysis: Hysteroscopy scope size and pain. Arch Gynecol Obstet 2015; 292:987-94. 